\title{
The Emerging Terbinafine-Resistant Trichophyton Epidemic: What Is the Role of Antifungal Susceptibility Testing?
}

\author{
Julia J. Shen ${ }^{a, b}$ Maiken C. Arendrup ${ }^{b, c, d}$ Shyam Verma ${ }^{e}$ \\ Ditte Marie L. Saunte ${ }^{a, b, c}$ \\ aDepartment of Dermatology, Zealand University Hospital, Roskilde, Denmark; bunit of Mycology, Department of \\ Bacteria, Parasites and Fungi, Statens Serum Institut, Copenhagen, Denmark; 'Department of Clinical Medicine, \\ Faculty of Health Science, University of Copenhagen, Copenhagen, Denmark; ${ }^{d}$ Department of Clinical Microbiology,

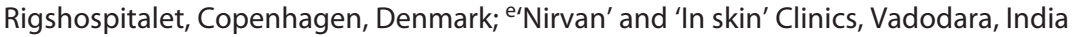

\section{Keywords}

Dermatophytes $\cdot$ Trichophyton $\cdot$ Terbinafine $\cdot$ Resistance $\cdot$ Antifungal susceptibility testing

\begin{abstract}
Background: Dermatophytosis is commonly encountered in the dermatological clinics. The main aetiological agents in dermatophytosis of skin and nails in humans are Trichophyton ( $T$.) rubrum, T. mentagrophytes and T. interdigitale (former T. mentagrophytes-complex). Terbinafine therapy is usually effective in eradicating infections due to these species by inhibiting their squalene epoxidase (SQLE) enzyme, but increasing numbers of clinically resistant cases and mutations in the SQLE gene have been documented recently. Resistance to antimycotics is phenotypically determined by antifungal susceptibility testing (AFST). However, AFST is not routinely performed for dermatophytes and no breakpoints classifying isolates as susceptible or resistant are available, making it difficult to interpret the clinical impact of a minimal inhibitory concentration (MIC). Summary: PubMed was systematically searched for terbinafine susceptibility testing
\end{abstract}

of dermatophytes on October 20,2020, by two individual researchers. The inclusion criteria were in vitro terbinafine susceptibility testing of Trichophyton (T.) rubrum, T. mentagrophytes and $T$. interdigitale with the broth microdilution technique. The exclusion criteria were non-English written papers. Outcomes were reported as MIC range, geometric mean, modal MIC and $\mathrm{MIC}_{50}$ and $\mathrm{MIC}_{90}$ in which 50 or $90 \%$ of isolates were inhibited, respectively. The reported MICs ranged from $<0.001$ to $>64 \mathrm{mg} / \mathrm{L}$. The huge variation in MIC is partly explained by the heterogeneity of the Trichophyton isolates, where some originated from routine specimens (wild types) whereas others came from non-responding patients with a known SQLE gene mutation. Another reason for the great variation in MIC is the use of different AFST methods where MIC values are not directly comparable. High MICs were reported particularly in isolates with SQLE gene mutation. The following SQLE alterations were reported: F397L, L393F, L393S, H440Y, F393I, F393V, F415I, F415S, F415V, S443P, A448T, L335F/A448T, S395P/A448T, L393S/ A448T, Q408L/A448T, F397L/A448T, I121M/V237I and $\mathrm{H} 440 \mathrm{Y} / \mathrm{F} 484 \mathrm{Y}$ in terbinafine-resistant isolates. karger@karger.com

(c) 2021 S. Karger AG, Basel

www.karger.com/drm
Correspondence to:

Ditte Marie L. Saunte, disa@ regionsjaelland.dk 


\section{Introduction}

Dermatophytes are slow-growing moulds with the ability to invade keratinised tissue such as skin, hair and nails [1]. They are classified into three groups depending on their natural habitat: geophilic (soil), zoophilic (animals) and anthropophilic (humans).

De Hoog et al. [2] revised the taxonomy of dermatophytes in 2017 and emphasised the importance of distinguishing between Trichophyton (T.) mentagrophytes (zoophilic strains) and T. interdigitale (anthropophilic strains) within the "T. mentagrophytes complex". Examples of other species in this complex are for example, $T$. quinckeanum (typical source of infection: cats, dogs and mice) [3], T. equinum (horse) [2] and T. erinacei (hedgehogs) [4]. However, the revised taxonomy is not yet fully implemented. Hence, the term T. mentagrophytes complex is commonly used, and the specific genotype of $T$. mentagrophytes which shows alarming resistance to terbinafine (TRB) is often referred to as T. interdigitale [58]. In this context, it is important to appreciate that the names used in this paper are the original published names used in the articles included in the review which may refer to species names used before the new classification was proposed in 2017. Therefore, some published T. interdigitale may not be $T$. interdigitale sensu stricto but rather a specific genotype of T. mentagrophytes, that is, T. mentagrophytes ITS genotype VIII, which has recently been identified to cause a morphologically atypical, often extensive, recalcitrant form of tinea corporis $[9,10]$.

The dermatophytes $T$. rubrum, $T$. interdigitale and $T$. mentagrophytes, are the main aetiological agents of dermatophytosis of skin and nails in humans [11-15]. The prevalence of skin mycosis is $14-25 \%$ worldwide $[16,17]$, which makes it one of the most common skin diseases $[12,18]$. Medical treatment of dermatophytosis consists of oral (e.g., TRB, itraconazole and griseofulvin) and/or topical antifungal agents (e.g., TRB, ketoconazole, ciclopirox, clotrimazole). TRB has been preferred as firstline agent against Trichophyton species because of its clinical efficacy and because TRB, in contrast to itraconazole, does not select for azole resistance in the colonising Candida microflora [19]. TRB is a fungicidal allylamine compound that interferes with ergosterol synthesis and thus the fungal cell membrane synthesis via its inhibition of the squalene epoxidase (SQLE) enzyme [20,21].

TRB therapy of dermatophytosis is usually effective, yet increasing numbers of non-responding cases have been documented [22-26]. Treatment failures and recurrences can be due to host factors such as poor compliance, drug interactions and in cases of onychomycosis local nail factors [27]. TRB resistance in dermatophytes is typically rare [28], but reports have been increasing since 2017. It is associated with various point mutations in the SQLE target gene of T. rubrum and T. interdigitale [22]. In India, TRB resistant dermatophytosis has become epidemic with common resistant or relapsing atypical and widespread ringworm infections $[10,29,30]$. Widespread use of over-the-counter topical creams containing a triple combination of antibacterial and antifungal agents, as well as a steroid may have contributed to the epidemic, as repeated exposures to sub-inhibitory concentrations of antifungals in an immunosuppressed environment caused by the steroid increases the risk of resistance [3133]. However, cases of TRB-resistant Trichophyton infections are also seen in other Asian and Middle Eastern countries such as Japan and Iran [21, 34, 35]. In Europe, resistant strains of $T$. rubrum and $T$. interdigitale with SQLE mutations have been identified in Switzerland [25], Germany [36, 37], Poland [38], Belgium [39] and Denmark [22-24].

\section{Clinical Signs of Antifungal Drug Resistance}

It would be ideal if the term "Treatment resistant dermatophytosis" was used exclusively to describe clinically resistant cases in which antifungal resistance had been confirmed both in vivo and in vitro either through susceptibility testing (demonstrating a high MIC) or molecularly (demonstrating a recognised resistance mutation). It is not possible in all countries to follow such a stringent definition. What is seen instead is "difficult to treat infections" with persistent superficial dermatophytosis including chronic (more than 6 months) and recurrent (reappearance of lesions 4 weeks after cessation of standard recommended treatment after clinical cure) forms with poor or no response to standard recommended treatment [31].

Certain clinical characteristics are useful indicators of drug resistance. The most important is a widespread dermatophytosis that has been previously treated, often with multiple regimens. These patients often present with large, sometimes coalescing lesions of superficial dermatophytosis with severe itching. In these cases, the lesions can range from highly inflammatory ones that are raised with erythema and variable scaling, to minimally inflammatory ones with uniform small whitish appearing scales. Most of the patients have concomitant tinea corporis and tinea cruris which often extends posteriorly to the perineum, posterior thighs and buttocks (Fig. 1). Tinea faciei often develops secondarily in these patients, at times ex- 


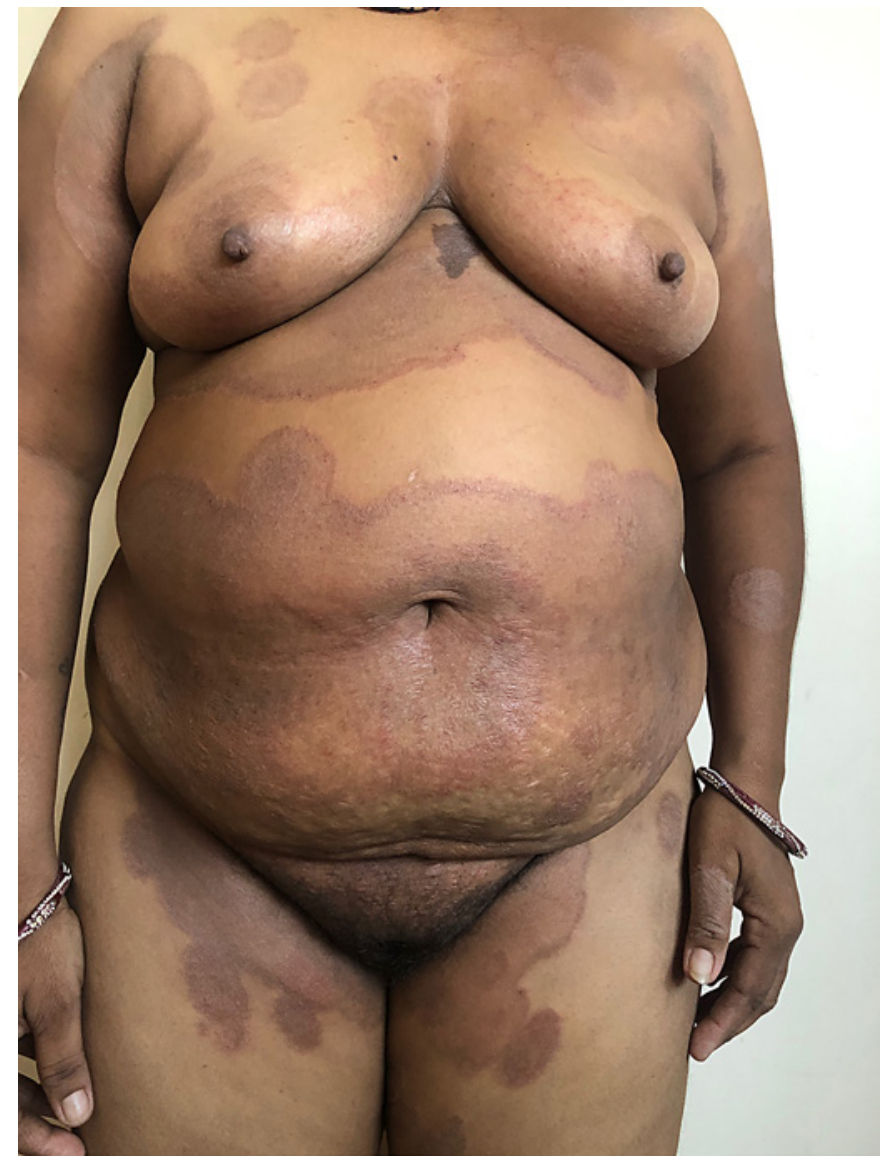

Fig. 1. Widespread dermatophytosis caused by T. mentagrophytes ITS genotype VIII.

tending from the neck to the face, including ears, and in some cases to the scalp, but usually not very far inside the hair margins. Occasionally, TRB resistance is seen in patients with a localised infection, which do not respond to treatment regimens that would normally cure the infection (Fig. 2).

\section{Antifungal Susceptibility Testing}

Resistance to antifungal compounds is determined by antifungal susceptibility testing (AFST). A micro-organism is defined as clinically susceptible (S) by a level of antimicrobial activity associated with a high likelihood of therapeutic success using a standard dosing regimen of the agent, whereas it is considered clinically resistant (R) when therapeutic failure is expected [40]. Various methods have been adopted for the testing of yeast or moulds including disk diffusion, agar dilution, E-test, flow cytometry and broth micro- and macrodilution techniques

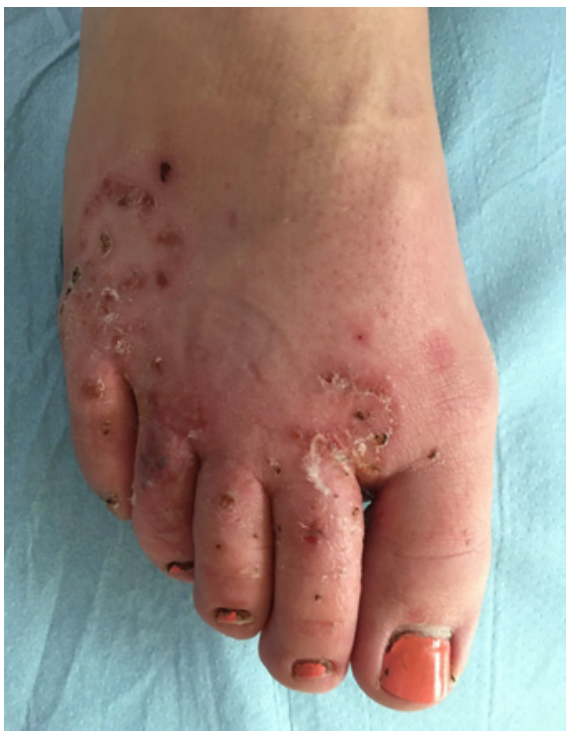

Fig. 2. Localised terbinafine resistant T. rubrum confirmed by EUCAST method E.Def 11.0 (45).

with or without a colour indicator $[31,41]$. AFST of dermatophytes is not routinely performed because it is complicated by the slow growth of the fungi and the associated risk of contamination, because no commercial susceptibility tests are validated for dermatophyte testing, because interpretative clinical breakpoints that allow interpretation of the specific MIC as susceptible or resistant have not been established, and because the false perception of low resistance rates creates an assumption that testing is not needed. Numerous critical parameters such as inoculum size, incubation time, type of microdilution plate, choice of medium and endpoint determination affect susceptibility test results. Currently, there are only two standardised techniques for in vitro AFST of dermatophytes; one from the Clinical Laboratory Standards Institute (CLSI) and the other from the European Committee on Antimicrobial Susceptibility Testing (EUCAST) $[42,43]$. Both of these reference methods are performed in microtitre plates containing broth culture media with serial dilutions of antifungal drugs, wherein a standardised amount of dermatophyte cells are added and the fungus growth is compared with positive and negative controls. The main differences of the two methods are that the CLSI method recommends a visual no-growth endpoint in round bottom plates, whereas the EUCAST adopted flat-bottom plates and an automated spectrophotometer reading to avoid subjectivity in endpoint determination. Moreover, the EUCAST has recently estab- 
Fig. 3. PRISMA flow diagram of the literature search.

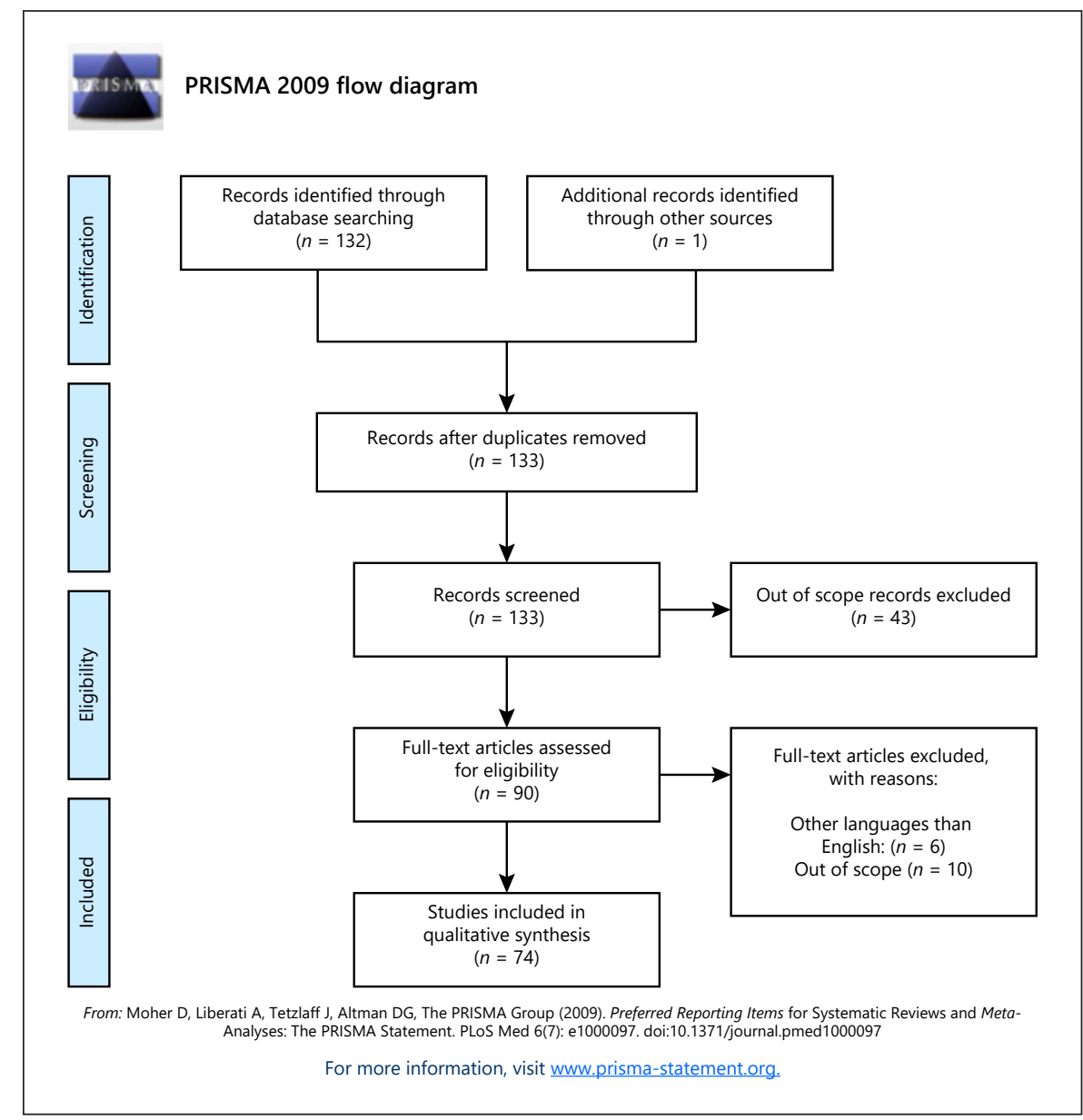

lished tentative epidemiological cut off values (ECOFFs, defined as the upper limit of the wild-type population [44]) that allows classification of the tested organism as either wild type (normal, and thus you can trust your clinical experience with respect to efficacy of medical treatment) or non-wild type (less susceptible than normal, and thus the dermatophyte may not respond as well to the typical therapy).

Despite the lack of routine susceptibility testing, increasing numbers of clinically resistant dermatophytes due to isolates with high TRB MICs and with target gene mutations have been reported in the past few years. This review evaluates the reported MICs for T. rubrum, T. mentagrophytes and T. interdigitale with the broth microdilution method in the literature and addresses the problem of extrapolation from the laboratory bench to patients.

\section{Method}

This systematic review was conducted in accordance with the PRISMA guidelines [45] (Fig. 3)

PubMed was searched for TRB susceptibility testing of T. rubrum, T. mentagrophytes and T. interdigitale with the following search string: ("disease susceptibility"[MeSH Terms] OR ("disease"[All Fields] AND "susceptibility"[All Fields]) OR "disease susceptibility"[All Fields] OR "susceptibility"[All Fields]) AND ("terbinafine"[MeSH Terms] OR "terbinafine"[All Fields]) AND ("trichophyton"[MeSH Terms] OR "trichophyton"[All Fields]). The literature search and screening were conducted on October 20, 2020, by two individual researchers (J.J.S. and D.M.L.S.). The inclusion criteria were in vitro terbinafine susceptibility testing of human isolates of T. rubrum, T. mentagrophytes and T. interdigitale with the broth microdilution technique. The exclusion criteria were papers in languages other than English. See Figure 1 for additional details of the literature search. Data from the included papers were extracted in a predefined Excel chart, and outcomes were reported as MIC range, MIC in which 50\% of isolates were inhibited $\left(\mathrm{MIC}_{50}\right)$, MIC in which $90 \%$ of isolates were inhibited $\left(\mathrm{MIC}_{90}\right)$, geometric mean (GM-MIC), most frequent MIC (Modal MIC), method, number of isolates and test material. Whenever data was not available this was stated as NA. 


\section{Results}

\section{T. interdigitale}

TRB susceptibility of a total of 829 T. interdigitale isolates were reported between 2001 and 2020 in 24 studies by the following reference standards: CLSI-M38-A2 (19 studies), EUCAST E.Def 11.0 (2 studies), EUCAST E.Def 9.3.1 (1 study), EUCAST E.Def 9.2 (1 study), CLSI-M38A (1 study) and CLSI-M38-P/NCCLS-M38-P (1 study) (Table 1). For all T. interdigitale isolates, the MIC ranged from 0.001 to $>32 \mathrm{mg} / \mathrm{L}$ ( 21 studies) using the CLSI/NCCLS method and from $<0.008$ to $>8 \mathrm{mg} / \mathrm{L}$ ( 4 studies) using the EUCAST method. Details of $\mathrm{MIC}_{50}, \mathrm{MIC}_{90}$, GMMIC and modal MIC are available in Table 1. Overall, 85 isolates were from patients with clinical failures, and two isolates were deemed resistant because of high MIC and SQLE mutations. For T. interdigitale isolates from clinically non-responding patients, the MIC ranged from $<0.015$ to $>32 \mathrm{mg} / \mathrm{L}$ and $<0.008$ to $>8$ using the CLSI/NCCLS method (6 studies) and EUCAST method (2 studies), respectively. Six studies performed SQLE gene sequencing detecting the following SQLE mutations: F397L, L393F and F397L/A448T. Three studies proposed the following breakpoints (susceptible $[S]$ and resistant $[R]$ ) for TRB against $T$. interdigitale strains using CLSI reference standard: $\mathrm{R} \geq 1 \mathrm{mg} / \mathrm{L}$ [46], $\mathrm{R} \geq 4 \mathrm{mg} / \mathrm{L}[12,47]$, and one study also using CLSI as reference proposed high TRB $\mathrm{MIC}$ at $\geq 2 \mathrm{mg} / \mathrm{L}$ [11]. One study [48] proposed the following wild-type upper limits (WT-UL) using EUCAST as reference standard: WT-UL $\leq 0.25 \mathrm{mg} / \mathrm{L}$ (by visual endpoint reading and spectrophotometric endpoint reading with a 90\% growth inhibition (spec-90\%), WT-UL $\leq 0.125$ $\mathrm{mg} / \mathrm{L}$ (by spectrophotometric endpoint reading with a $50 \%$ growth inhibition [spec-50\%]). The spec-50\% WTUL values have subsequently been accepted as EUCAST tentative ECOFF for the EUCAST 11.0 method [43].

\section{T. mentagrophytes}

TRB susceptibility of a total of 1,399 T. mentagrophytes isolates were reported between 1995 and 2020 in 41 studies by the following reference standards: CLSI-M38-A2 (18 studies), CLSI-M38-A/NCCLS-M38-A (10 studies), CLSI-M38-P/NCCLS-M38-P (5 study), CLSI-M38 (1 study), CLSI-M27-A/NCCLS-M27-A (3 studies), EUCAST E.Def 9.3.1 (1 study), EUCAST E.Dis 7.1 (1 study) and unspecified broth microdilution method (2 studies) (Table 1). For all T. mentagrophytes isolates, the MIC ranged from 0.001 to $>32 \mathrm{mg} / \mathrm{L}$ using the CLSI/NCCLS method ( 37 studies) and $<0.007$ to $4 \mathrm{mg} / \mathrm{L}$ using EUCAST method (2 studies) (Table 1). For T. mentagrophytes iso- lates with clinical resistance, the MIC ranged from 0.015 to $>32 \mathrm{mg} / \mathrm{L}$ using the CLSI/NCCLS method (5 studies), and one EUCAST study reported TRB MIC $4 \mathrm{mg} / \mathrm{L}$ [39]. Overall, 36 isolates were from patients with clinical failures, and 210 isolates were suspected as clinically resistant because of high MIC and SQLE mutations. Five studies performed SQLE gene sequencing detecting the following SQLE mutations: F397L, L393F, L393S, H440Y, S443P, A448T, L335F/A448T, S395P/A448T, L393S/ A448T, Q408L/A448T and F397L/A448T. Two studies using the CLSI reference method defined TRB resistance as $\mathrm{R} \geq 1 \mathrm{mg} / \mathrm{L}$ [9] and $\mathrm{R} \geq 4 \mathrm{mg} / \mathrm{L}$ [47].

\section{T. mentagrophytes-T. interdigitale complex}

TRB susceptibility of a total of 548 isolates reported as belonging to the T. mentagrophytes-T. interdigitale complex were reported between 2019 and 2020 in 4 studies by the CLSI-M38-A2 reference standard (Table 1). For all $T$. mentagrophytes- $T$. interdigitale complex isolates, the MIC ranged from 0.015 to $32 \mathrm{mg} / \mathrm{L}$ (4 studies). Overall, 16 isolates were from patients with clinical failures, and 74 isolates were suspected as clinically resistant because of high MIC and SQLE mutations. The MIC ranged from 1 to $32 \mathrm{mg} / \mathrm{L}$ (3 studies). Three studies that performed SQLE gene sequencing detected the following SQLE mutations: F397L and Q408L. One study proposed WT-UL $\leq 8 \mathrm{mg} / \mathrm{L}$ [5], and one study proposed high TRB MIC at $>2 \mathrm{mg} / \mathrm{L}$ [6] both using CLSI as reference standard.

\section{T. rubrum}

In the years between 1995 and 2020, 62 out of the 74 included studies tested TRB susceptibility of T. rubrum with the following standards: CLSI-M38-A2 (31 studies), CLSI-M38-A/NCCLS-M38-A (13 studies), CLSI-M38-P/ NCCLS-M38-P (8 studies), CLSI-M27-A/NCCLS-M27A (4 studies) EUCAST E.Def 11.0 (2 studies), EUCAST E.Def 9.3.1 (1 study), EUCAST E.Def 9.2 (1 study), EUCAST E.Dis 7.1 (1 study) and unspecified broth microdilution method (3 studies) (Table 2). A total of 2,235 T. rubrum isolates were included, of which 113 isolates were from patients with clinical resistance, and 26 isolates were suspected as clinically resistant because of high MICs and SQLE mutations. The MICs for all T. rubrum isolates ranged from $<0.001$ to $>64 \mathrm{mg} / \mathrm{L}$ using the CLSI/NCCLS method (56 studies) and $<0.008$ to $>8 \mathrm{mg} / \mathrm{L}$ using the EUCAST method (5 studies) (Table 2). For T. rubrum isolates with clinical resistance, the MIC ranged from 0.003 to $>32 \mathrm{mg} / \mathrm{L}$ using the CLSI/NCCLS method (8 studies) and 0.03 to $>8 \mathrm{mg} / \mathrm{L}$ using the EUCAST method ( 2 studies). Two studies performed SQLE gene sequencing de-
64

Dermatology 2022;238:60-79 DOI: $10.1159 / 000515290$
Shen/Arendrup/Verma/Saunte 


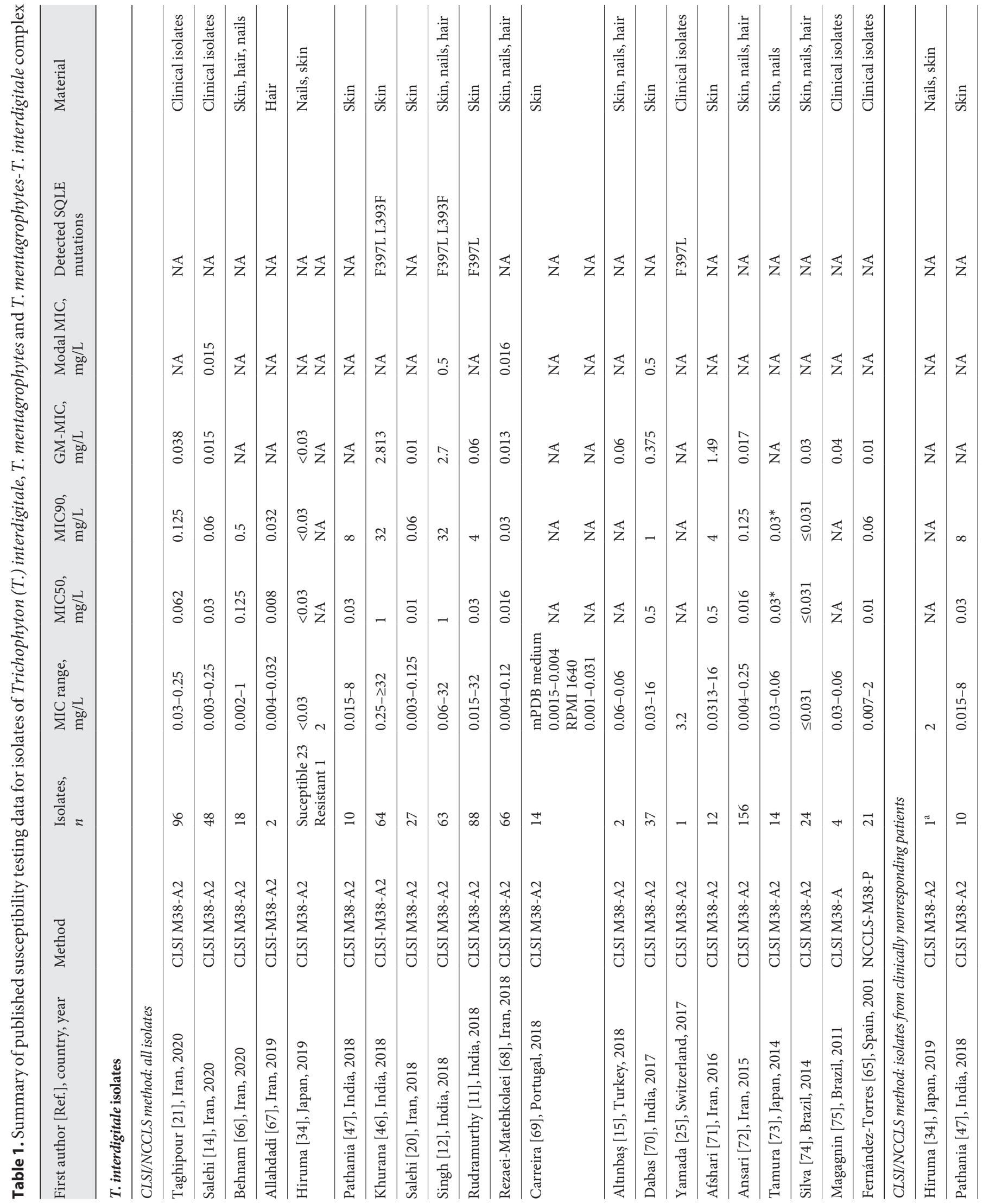




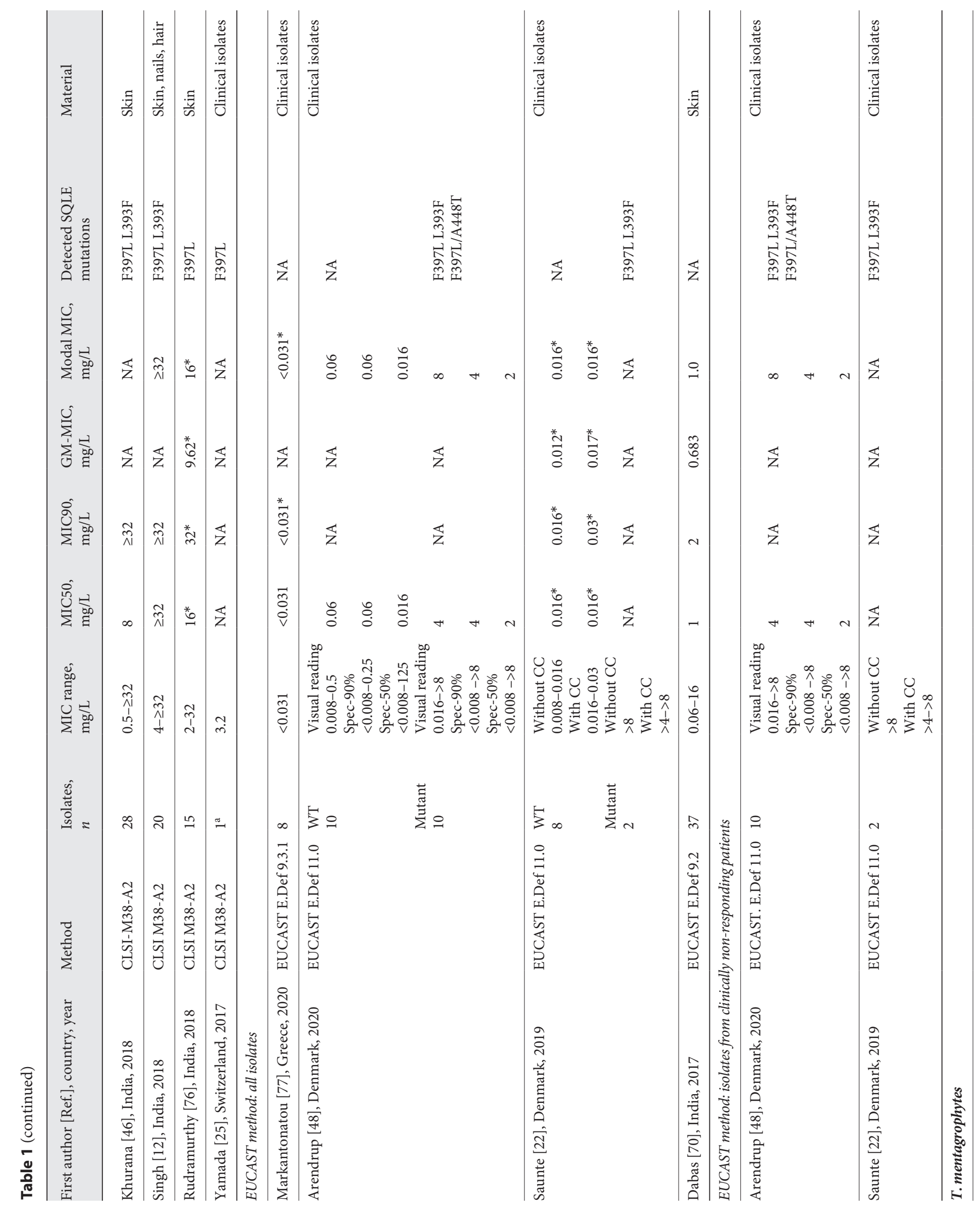




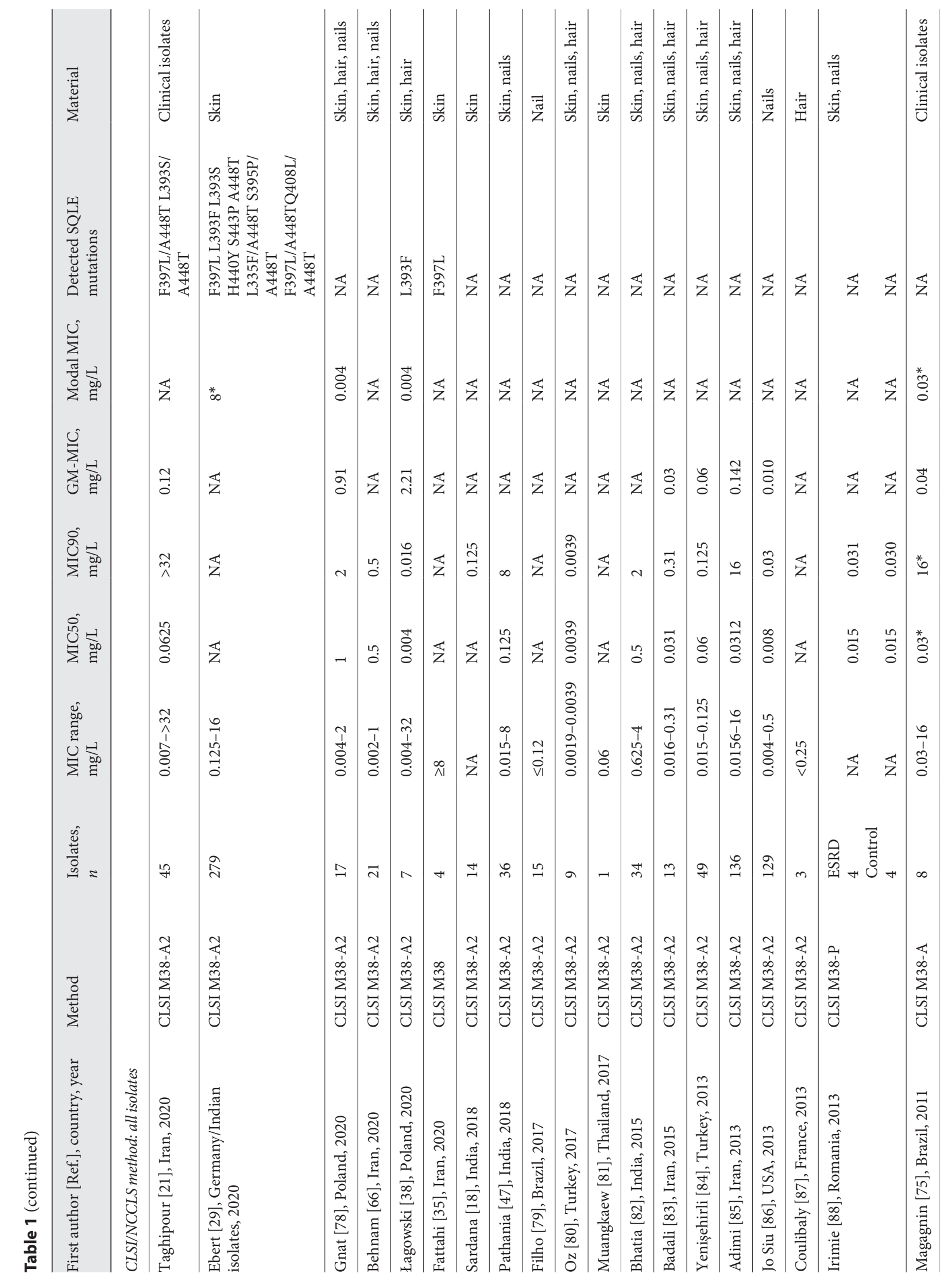




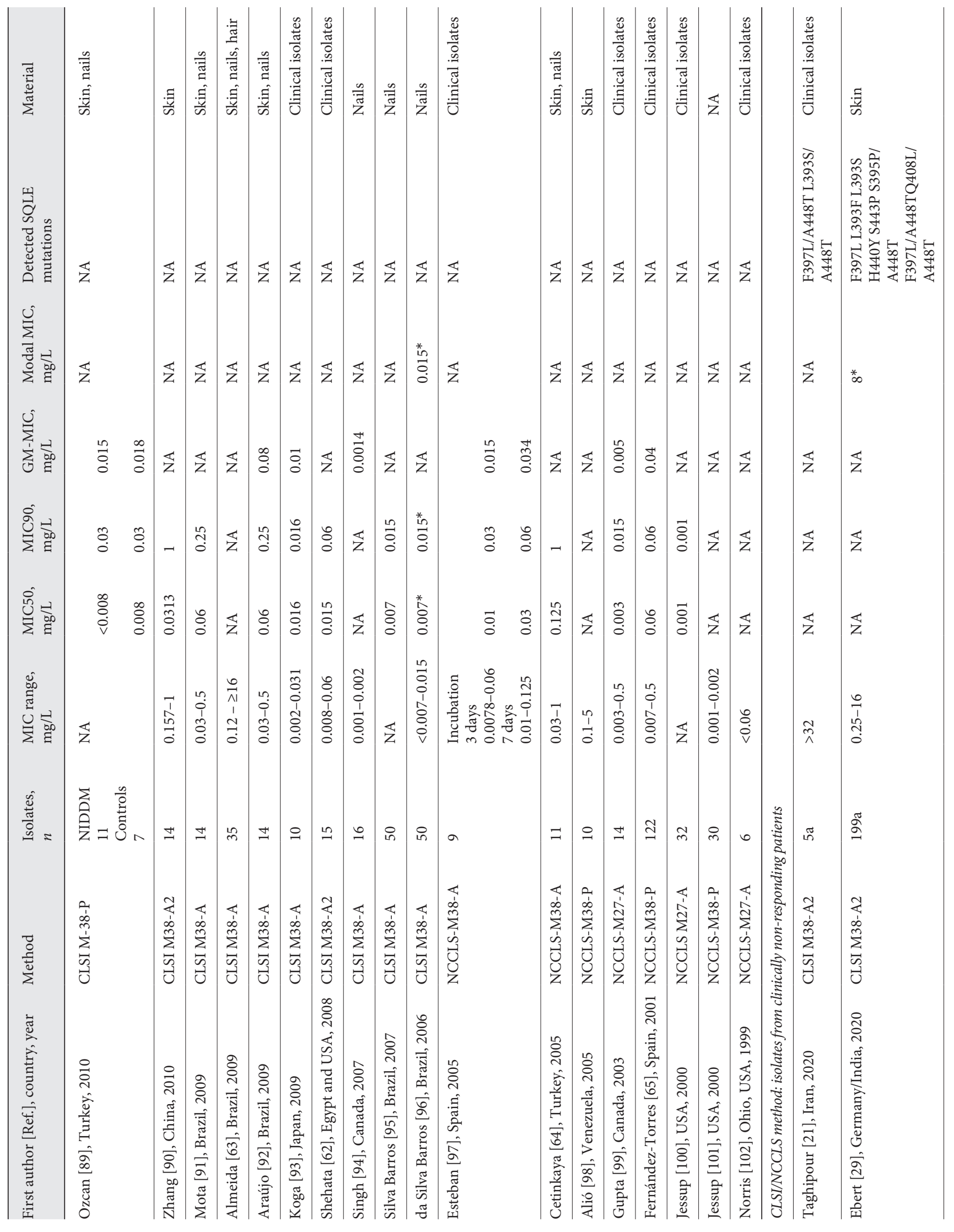




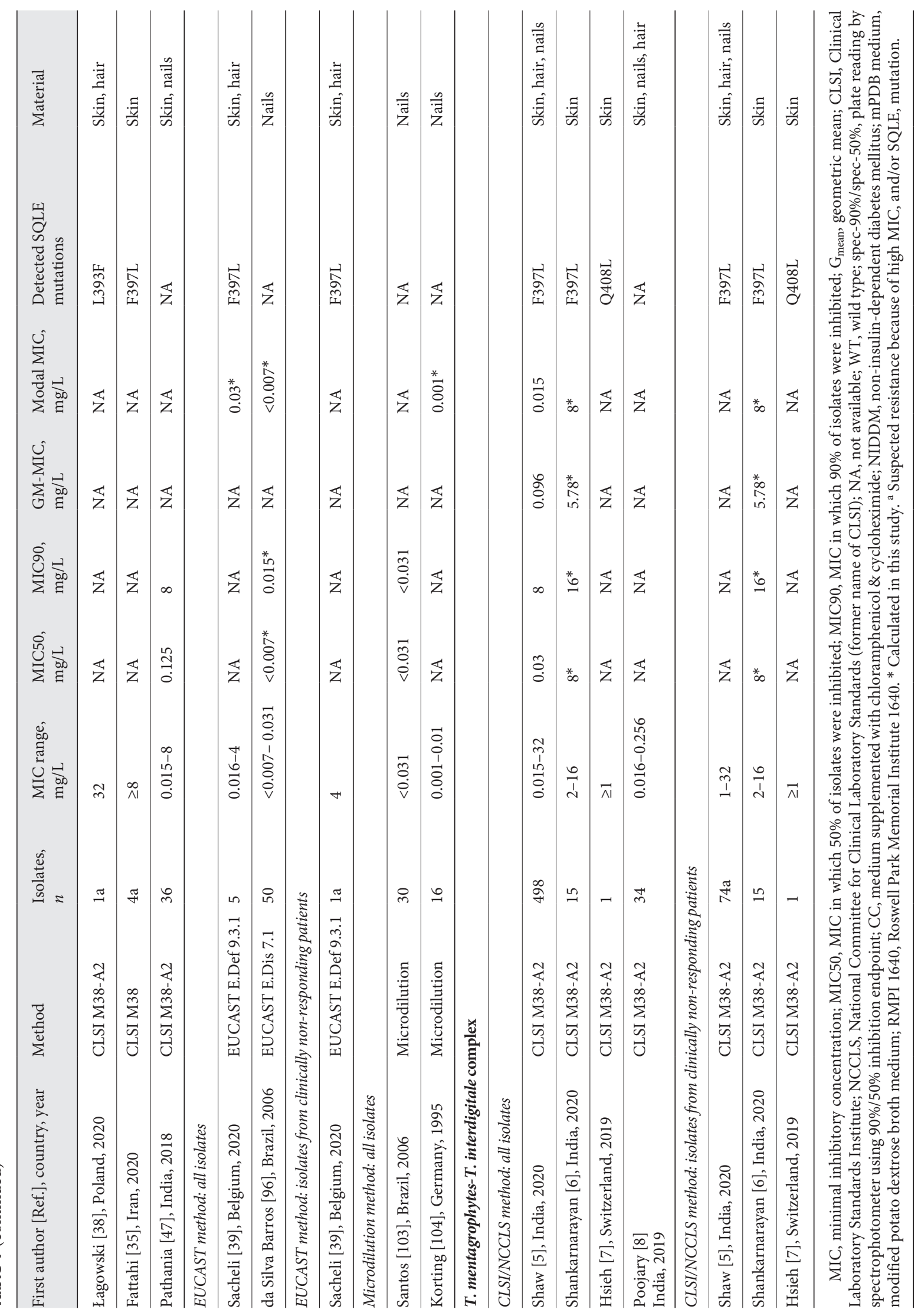




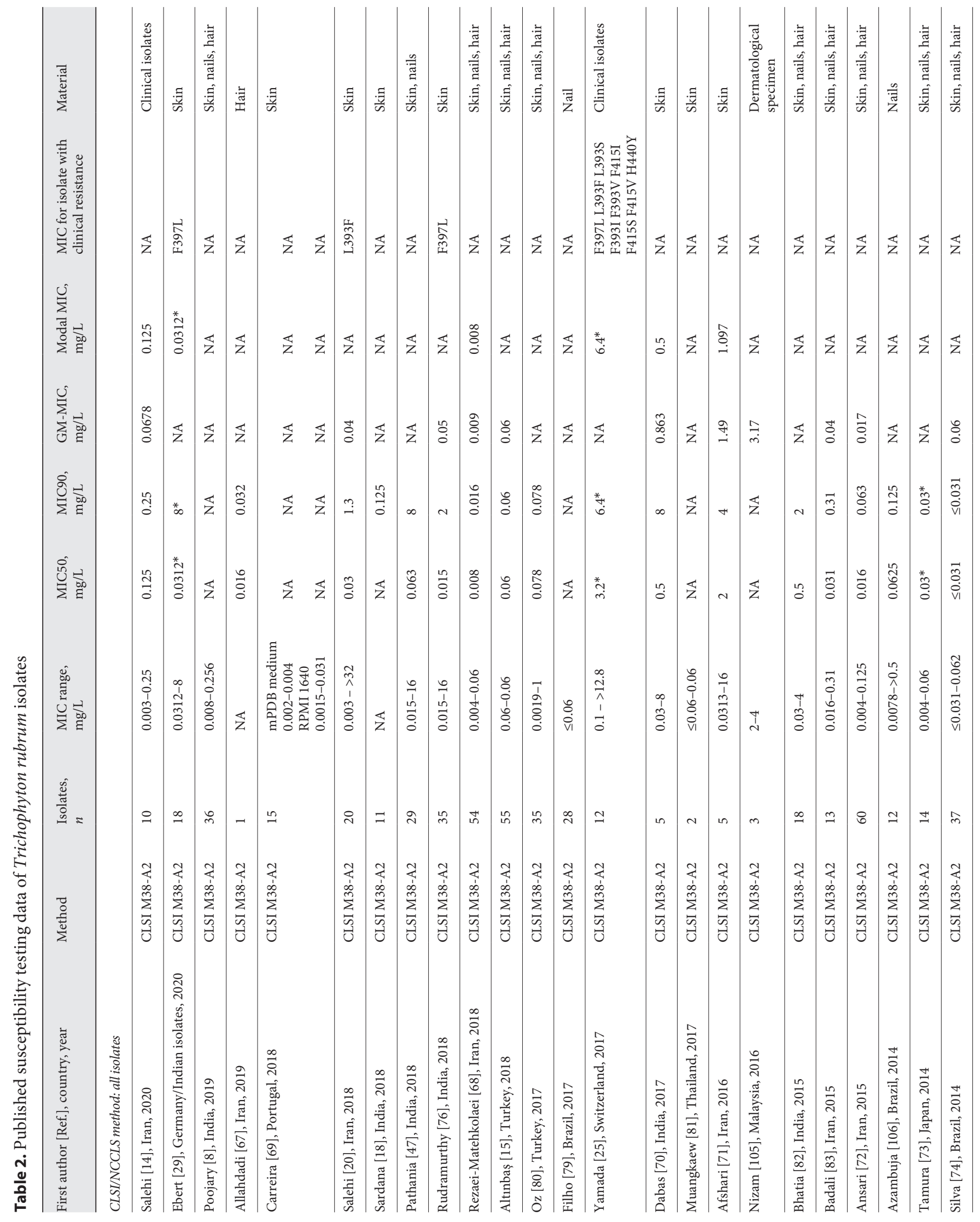




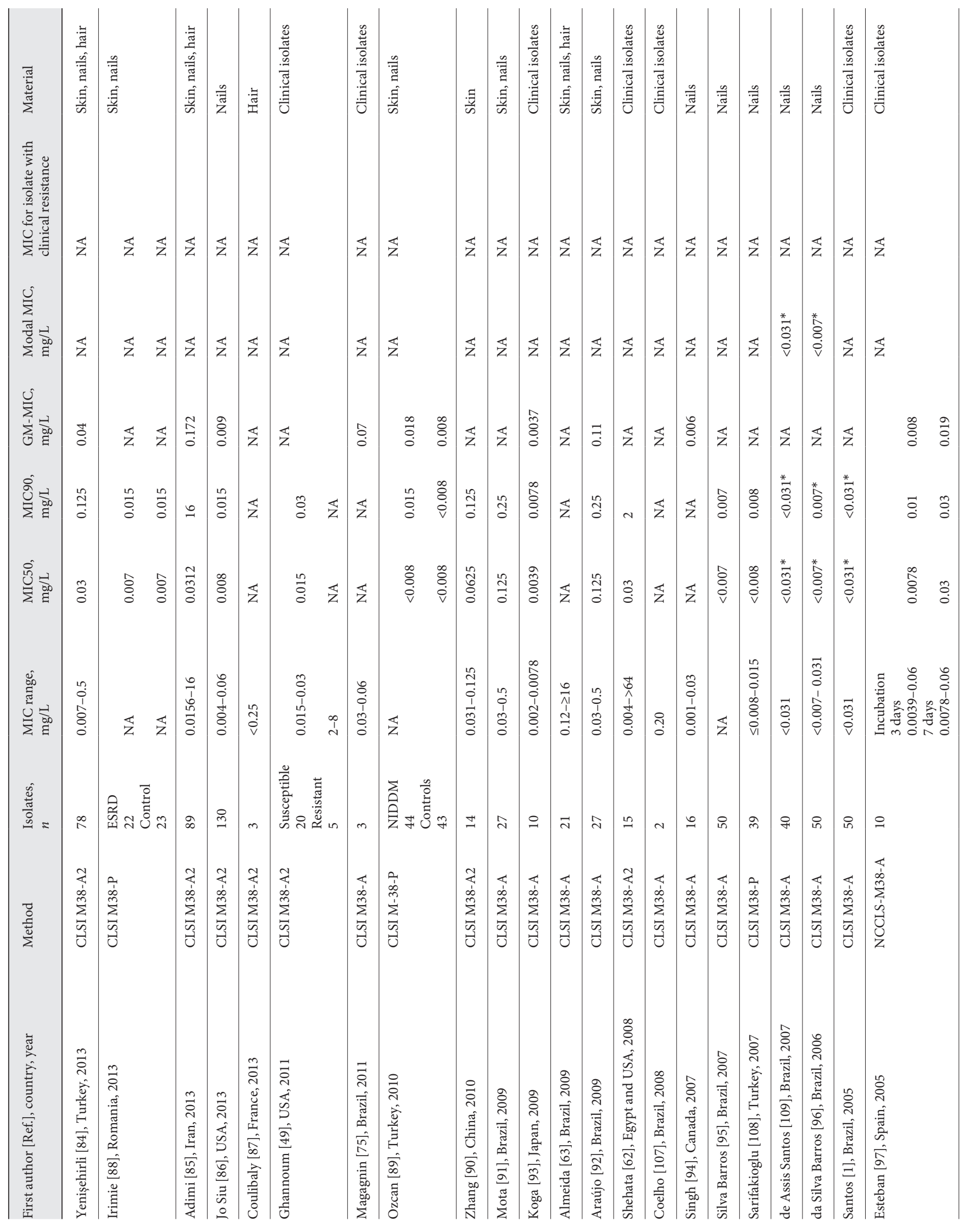




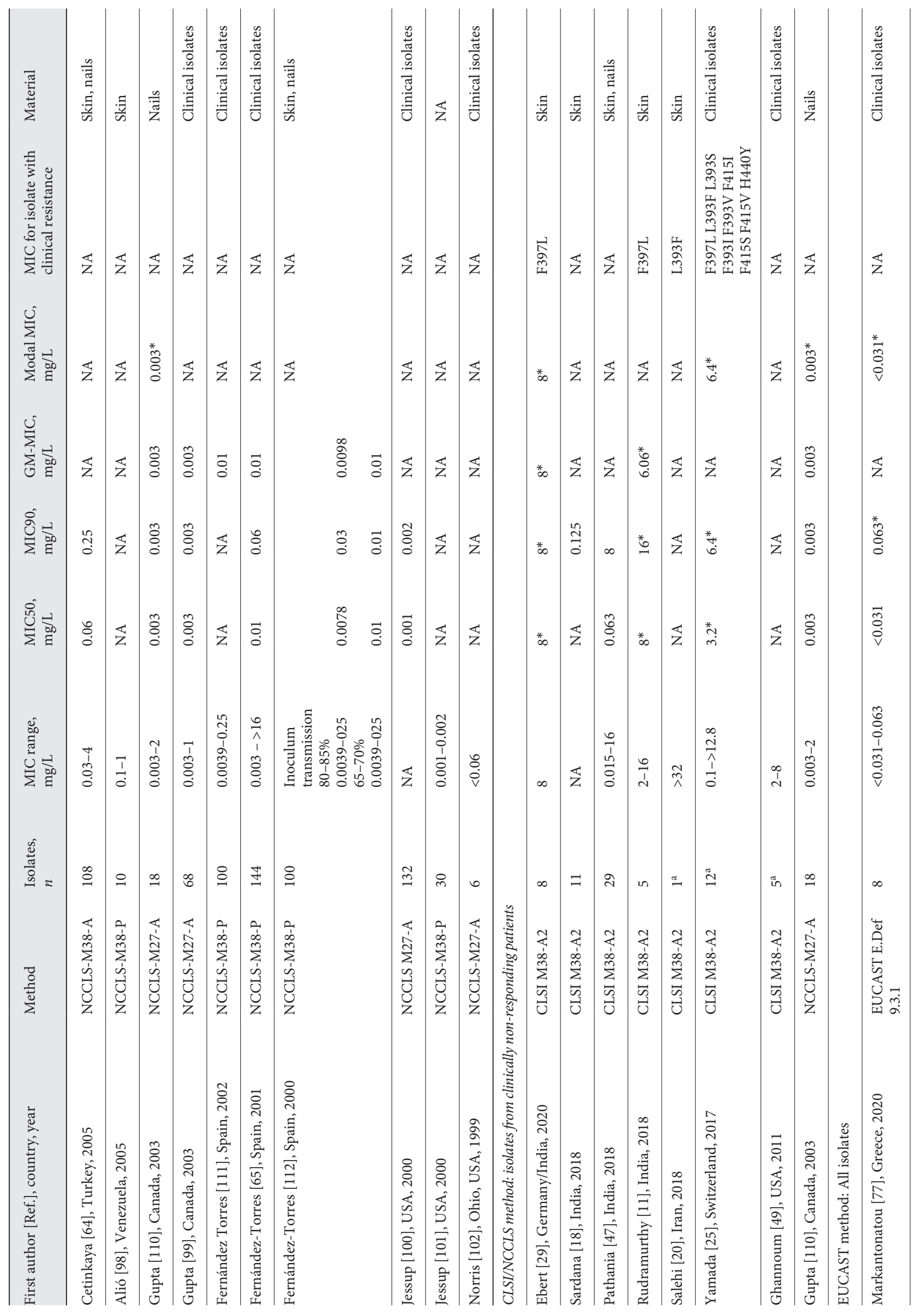




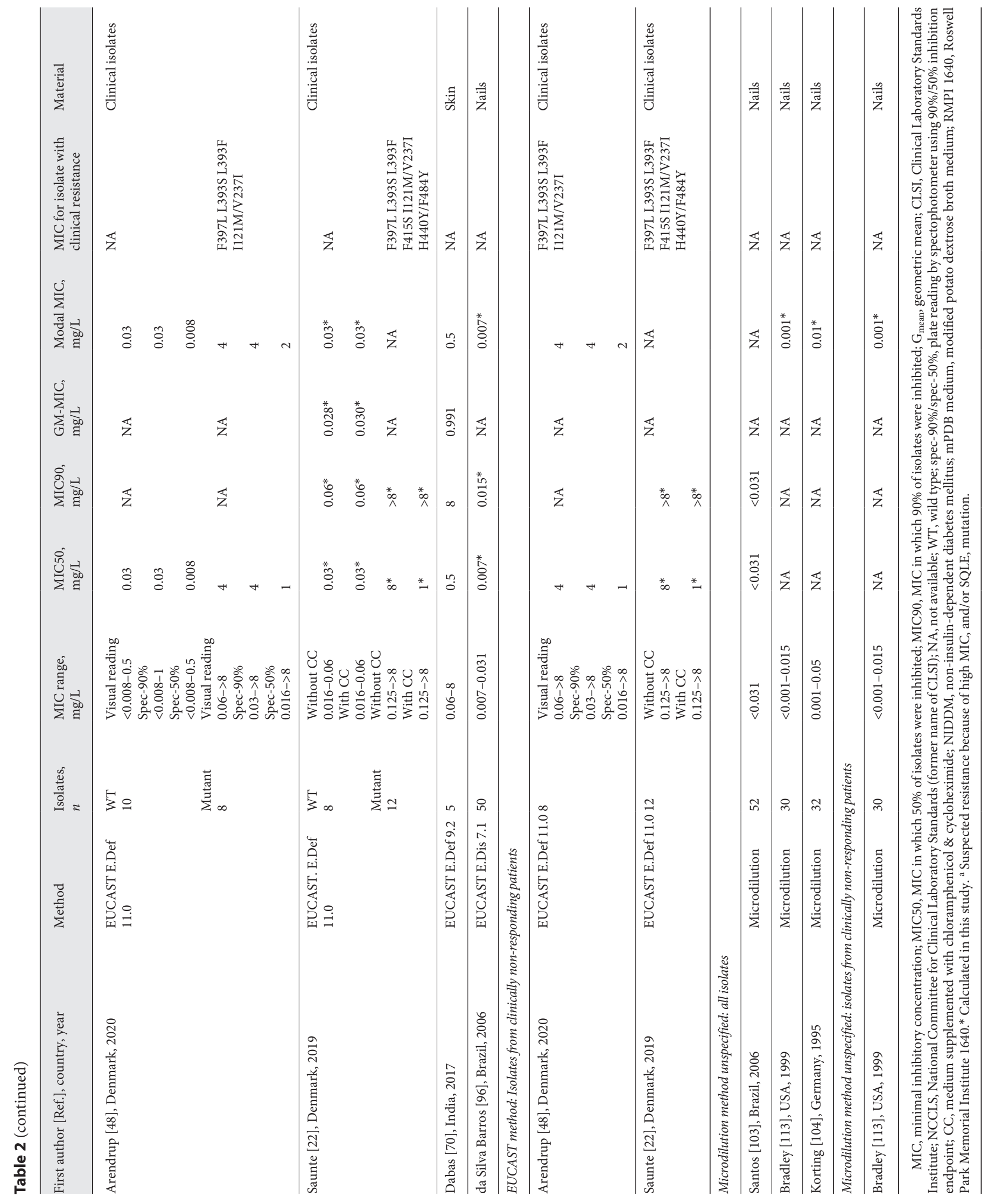


tecting the following SQLE mutations: F397L, L393F, L393S, H440Y, F393I, F393V, F415I, F415S, F415V, I121M/V237I and H440Y/F484Y. Three studies using the CLSI reference standard proposed the following breakpoints for T. rubrum strains: TRB resistance was defined as $\mathrm{R} \geq 1 \mathrm{mg} / \mathrm{L}[18,49], \mathrm{R} \geq 4 \mathrm{mg} / \mathrm{L}$ [47], and one study proposed high TRB MIC at $\geq 2 \mathrm{mg} / \mathrm{L}$ [11]. One study using EUCAST protocol reported following WT-UL: WT-UL $\leq 0.125 \mathrm{mg} / \mathrm{L}$ (by visual and spec-90\% endpoint reading) [48], WT-UL $\leq 0.03 \mathrm{mg} / \mathrm{L}$ (with spec-50\% endpoint reading in plates containing chloramphenicol and cycloheximide [CC]) [48], $\mathrm{S} \leq 0.06 \mathrm{mg} / \mathrm{L}$ (with spec-50\% endpoint reading in plates without $\mathrm{CC}$ ) [48], and one study proposed ECOFF of 0.06 or 0.125 [22]. EUCAST has recently established a tentative ECOFF with the spec-50\% endpoint reading of $0.03 \mathrm{mg} / \mathrm{L}$ for T. rubrum and E.Def 11.0 [43].

\section{Discussion}

The number of patients with clinical and laboratoryconfirmed TRB-resistant dermatophytosis is rising [5, 22]. Until this autumn (2020), there were no official guidelines on how to interpret the results and furthermore, there is a huge intraspecies variation in reported MIC values for the most prevalent species T. rubrum, $T$. mentagrophytes and T. interdigitale. This variation can be due to different methods in AFST and technical issues related to testing, or it can reflect true differences in susceptibility due to acquisition of point mutations in the SQLE gene altering the binding site of TRB and conferring loss of susceptibility to TRB therapy $[11,12,22,28$, 48].

However, clinical resistance does not always correspond to the in vitro resistance and vice versa. This is because several factors influence outcome of an infection including the severity of infection, the host immunity, the timing and dosing of the therapy, compliance and the susceptibility of the infecting organism. A newer study from 2018 investigated risk factors and performed AFST of both T. rubrum and T. interdigitale strains from 39 recurrent and clinically unresponsive tinea corporis and tinea cruris patients [47]. TRB MIC ranging from 0.015 to 16 $\mathrm{mg} / \mathrm{L}$ were found, including $1 \mathrm{~T}$. interdigitale and $3 \mathrm{~T}$. rubrum isolates with MICs of $>2 \mathrm{mg} / \mathrm{L}$, which is only $10 \%$ of the total number of clinically resistant cases. The authors concluded that most of the strains were not drug resistant, and the increase in MIC was not the only factor responsible for clinical resistance in dermatophytosis.
The management of TRB-resistant infections is challenging as few alternatives are available. There is compelling evidence that itraconazole is the preferred agent for TRB-resistant Trichophyton infections [5, 29, 33, 50, 51]. The optimal dosing regimen and treatment duration, however, have not been established. Consequently, practises vary, and elevated doses above $200-400 \mathrm{mg}$ daily are sometimes adopted for prolonged duration despite lack of scientific rationale or clinical validation $[52,53]$. The current prevailing sentiment in India is to reduce unnecessary prescription of itraconazole as an attempt to avoid emergence of itraconazole resistance in Trichophyton as emergence of multidrug resistant infections would have grave consequences. Azole resistant dermatophytes have previously been reported [54], and few cases have been found to be resistant to griseofulvin since the 1960s [55, 56]. Cross-resistance within the same antifungal group has also been noted for example, resistance to other allylamines (e.g., butenafine, naftifine) in TRB-resistant isolates [57]. The antifungal mode of action differs, as azoles and TRB both inhibit the ergosterol biosynthesis (but inhibit different enzymes), and griseofulvin interferes with the microtubule formation $[58,59]$. Nevertheless, multidrug resistance to several drug classes has been reported after serial passages on drug containing agars in vitro [60]. Moreover, multidrug resistance has been sporadically reported in the clinical setting of TRB-resistant T. mentagrophytes/interdigitale infection in India [59]. The Indian epidemic is probably somewhat unique and explained by the emergence of a new and more virulent $T$. mentagrophytes subspecies (genotype VIII) in response to a high use of antifungal agents potentially facilitated/enhanced by an animal reservoir and challenges in infection control due to crowded housing conditions. However, TRB resistance is increasing elsewhere despite the lack of routine testing and the prevalence of multidrug resistance largely unknown [10, 18, 29, 37].

Interpretative clinical breakpoint values were not established until recently. CLSI has noted that most TRB MICs are $\leq 0.25 \mathrm{mg} / \mathrm{L}$ for dermatophytes [61]. This value is, however, several fold higher than the recommended CLSI MIC range for the T. mentagrophytes quality control strain $(0.002-0.008 \mathrm{mg} / \mathrm{L})$ raising a concern that not all isolates with a MIC up towards $0.25 \mathrm{mg} / \mathrm{L}$ may be without resistance mechanisms and clinically susceptible. Of note, some studies using the CLSI method suggest even higher breakpoints for resistance for $T$. interdigitale between $\geq 1$ and $\geq 4 \mathrm{mg} / \mathrm{L}[11,12,46,47], T$. mentagrophytes between $\geq 1$ and $\geq 4 \mathrm{mg} / \mathrm{L}[18,47]$, T. rubrum between $\geq 1$ and $\geq 4$ $\mathrm{mg} / \mathrm{L}[18,47,49]$ and T. mentagrophytes-T. interdigitale
Shen/Arendrup/Verma/Saunte 
complex WT-UL $\leq 8 \mathrm{mg} / \mathrm{L}$ [5]. Thus, further standardisation and establishment of CLSI breakpoints are urgently needed.

Recently, EUCAST developed a reference method that allows an automated endpoint reading and provides quality control ranges for several control strains [43]. This method will facilitate improved inter-laboratory reproducibility. Moreover, tentative ECOFFs were established which allow classification of isolates as wild type or non-wild type. Several aspects are considered and integrated into the process of setting breakpoints for antifungal agents. These include dosing information, MIC distributions, ECOFF setting, pharmacokinetics, pharmacodynamics and clinical outcome data. Until such data is available, adoption of the EUCAST method with the tentative ECOFFs will allow guidance for TRB, itraconazole and voriconazole use against T. rubrum and $T$. interdigitale. Wildtype isolates are "normal" and will respond "normally" to treatment, meaning the clinician can expect the typical outcome for treatment with a specific drug-bug combination. Non-wild-type isolates may or may not respond to therapy depending on the degree of MIC elevation and the drug exposure that can be obtained. A rule of thumb is nevertheless, that the clinician should consider if alternative therapy would be warranted. Most important is to realise that MICs, ECOFFs and breakpoints are method dependent, and just like a distance is a different number if measured in metres or feet, MIC values across methods will vary and can only be interpreted correctly by the method-specific associated ECOFFs and breakpoints. This is also true for susceptibility results obtained by commercial test systems. Such results are only reliable if the method is correctly standardised against the reference method from which the breakpoints are adopted.

\section{Conclusion}

Overall, high TRB MICs were reported in the dermatology literature for T. mentagrophytes, $T$. interdigitale and T. rubrum and more than 15 individual target protein alterations have been identified in isolates from treatment-resistant cases [62-65]. Clinically, the number of patients with resistant dermatophytosis is also rising, supporting the increasing clinical relevance of AFST in non-responding cases and where resistance is prevalent $[5,10,22]$. AFST is unfortunately not considered a routine test but recent progress allows for standardisation and a broader implementation of dermatophyte suscep- tibility testing. Hopefully, this will help bring AFST a step closer to becoming a routine test and guide, as susceptibility testing is for so many other infections.

\section{Key Message}

Clinical suspected terbinafine resistance can be mycologically proven by microdilution methods. Recent progress allows for standardisation.

\section{Acknowledgement}

The authors thank the patients for giving permission to use their photos and Dr. Lisa Travis for English proofreading.

\section{Statement of Ethics}

Written informed consent was obtained from the patients for publication of the details of their medical case and any accompanying images.

\section{Conflict of Interest Statement}

M.C. Arendrup has, outside the current work, received research grants/contract work (paid to the SSI) from Amplyx, Basilea, Cidara, F2G, Gilead, Novabiotics, Scynexis and T2Biosystems and speaker honoraria (personal fee) from Astellas, Gilead, MSD, and SEGES over the past 5 years. She is the current chairman of the EUCAST-AFST.

S. Verma has delivered one lecture and has attended an "Ad Board meeting" once, both organised by Janssen Pharmaceuticals, India, for which he received a honorarium.

D.M.L. Saunte was a paid consultant for advisory board meetings by AbbVie, Janssen, Sanofi, Leo Pharma and received speaker's honoraria and/or received grants from the following companies: Abbvie, Desitin, Pfizer, Galderma, Novartis and Leo Pharma during the last 5 years.

J.J. Shen has no conflict of interests.

\section{Funding Sources}

J.J. Shen received a research grant from the Dept. of Dermatology, Zealand University Hospital, Roskilde, Denmark.

\section{Author Contributions}

D.M.L. Saunte initiated the article, J.J. Shen and D.M.L. Saunte performed the systematic review of included articles. All authors wrote and critically reviewed the manuscript. All authors have accepted the final version of the manuscript. 


\section{References}

1 Santos DA, Hamdan JS. Evaluation of broth microdilution antifungal susceptibility testing conditions for Trichophyton rubrum. J Clin Microbiol. 2005;43(4):1917-20.

2 de Hoog GS, Dukik K, Monod M, Packeu A, Stubbe D, Hendrickx M, et al. Toward a Novel Multilocus Phylogenetic Taxonomy for the Dermatophytes. Mycopathologia. 2017; 182(1-2):5-31.

3 Uhrlaß S, Schroedl W, Mehlhorn C, Krüger C, Hubka V, Maier T, et al. Molecular epidemiology of Trichophyton quinckeanum - a zoophilic dermatophyte on the rise. J Dtsch Dermatol Ges. 2018;16(1):21-32.

4 Nenoff P, Krüger C, Ginter-Hanselmayer G, Tietz HJ. Mycology-an update. Part 1: Dermatomycoses: Causative agents, epidemiology and pathogenesis. JDDG - J Ger Soc Dermatology. 2014;12(3):188-210.

5 Shaw D, Singh S, Dogra S, Jayaraman J, Bhat R, Panda S, et al. MIC and Upper Limit of Wild-Type Distribution for 13 Antifungal Agents against a Trichophyton mentagrophytes-Trichophyton interdigitale Complex of Indian Origin. Antimicrob Agents Chemother. 2020;64(4):e01964-19.

6 Shankarnarayan SA, Shaw D, Sharma A, Chakrabarti A, Dogra S, Kumaran MS, et al. Rapid detection of terbinafine resistance in Trichophyton species by Amplified refractory mutation system-polymerase chain reaction. Sci Rep. 2020;10(1):1297-6.

7 Hsieh A, Quenan S, Riat A, Toutous-Trellu L, Fontao L. A new mutation in the SQLE gene of Trichophyton mentagrophytes associated to terbinafine resistance in a couple with disseminated tinea corporis. J Mycol Med. 2019; 29(4):352-5.

8 Poojary S, Miskeen A, Bagadia J, Jaiswal S, Uppuluri P. A Study of In vitro Antifungal Susceptibility Patterns of Dermatophytic Fungi at a Tertiary Care Center in Western India. Indian J Dermatol. 2019;64(4):27784.

9 Nenoff P, Verma SB, Uhrlaß S, Burmester A, Gräser Y. A clarion call for preventing taxonomical errors of dermatophytes using the example of the novel Trichophyton mentagrophytes genotype VIII uniformly isolated in the Indian epidemic of superficial dermatophytosis. Mycoses. 2019;62(1):6-10.

10 Nenoff P, Verma SB, Vasani R, Burmester A, Hipler U-C, Wittig F, et al. The current Indian epidemic of superficial dermatophytosis due to Trichophyton mentagrophytes-A molecular study. Mycoses. 2019 Apr;62(4): 336-56.

11 Rudramurthy SM, Shankarnarayan SA, Dogra S, Shaw D, Mushtaq K, Paul RA, et al. Mutation in the squalene epoxidase gene of Trichophyton interdigitale and Trichophyton rubrum associated with allylamine resistance. Antimicrob Agents Chemother. 2018 Mar; 62(5):1-9.
12 Singh A, Masih A, Khurana A, Singh PK, Gupta M, Hagen F, et al. High terbinafine resistance in Trichophyton interdigitale isolates in Delhi, India harbouring mutations in the squalene epoxidase gene. Mycoses. 2018; 61(7):477-84.

13 Adimi P, Jamal Hashemi S, Mahmoudi M, Mirhendi H, Reza Shidfar M, Emmami M, et al. In-vitro Activity of 10 Antifungal Agents against 320 Dermatophyte Strains Using Microdilution Method in Tehran. Iran J Pharm Res. 2013;12(3):537-45.

14 Salehi Z, Fatahi N, Taran M, Izadi A, Badali $\mathrm{H}$, Hashemi SJ, et al. Comparison of in vitro antifungal activity of novel triazoles with available antifungal agents against dermatophyte species caused tinea pedis. J Mycol Med. 2020.

15 Altinbaş R, Özakkaş F, Bariş A, Turan D, Şen S. In vitro susceptibility of seven antifungal agents against dermatophytes isolated in İstanbul. Turkish J Med Sci. 2018;48(3):6159.

16 Vos T, Flaxman AD, Naghavi M, Lozano R, Michaud C, Ezzati M, et al. Years lived with disability (YLDs) for 1160 sequelae of 289 diseases and injuries 1990-2010: a systematic analysis for the Global Burden of Disease Study 2010. Lancet. 2012 Dec;380(9859):2163-96.

17 Havlickova B, Czaika VA, Friedrich M. Epidemiological trends in skin mycoses worldwide. Mycoses. 2008;51(Suppl):2-15.1

18 Sardana K, Kaur R, Arora P, Goyal R, Ghunawat $S$. Is antifungal resistance a cause for treatment failure in dermatophytosis: A study focused on tinea corporis and cruris from a tertiary centre? Indian Dermatol Online J. 2018;9(2):90.

19 Chen X, Jiang X, Yang M, González U, Lin X, Hua $X$, et al. Systemic antifungal therapy for tinea capitis in children. Cochrane Database Syst Rev. 2016 May 12;(5):CD004685.

20 Salehi Z, Shams-Ghahfarokhi M, RazzaghiAbyaneh M. Antifungal drug susceptibility profile of clinically important dermatophytes and determination of point mutations in terbinafine-resistant isolates. Eur J Clin Microbiol Infect Dis. 2018;37(10):1841-6.

21 Taghipour S, Shamsizadeh F, Pchelin IM, Rezaei-Matehhkolaei A, Mahmoudabadi AZ, Valadan R, et al. Emergence of terbinafine resistant trichophyton mentagrophytes in iran, harboring mutations in the squalene epoxidase (Sqle) gene. Infect Drug Resist. 2020;13: $845-50$.

22 Saunte DML, Hare RK, Jørgensen KM, Jørgensen R, Deleuran M, Zachariae CO, et al. Emerging terbinafine resistance in Trichophyton: Clinical characteristics, squalene epoxidase gene mutations, and a reliable EUCAST method for detection. Antimicrob Agents Chemother. 2019;63(10):1-9.
23 Wingfield Digby SS, Hald M, Arendrup MC, Hjorth SV, Kofoed K. Darier disease complicated by terbinafine-resistant Trichophyton rubrum: A case report. Acta Derm Venereol. 2017;97(1):139-40.

24 Schøsler L, Andersen LK, Arendrup MC, Sommerlund M. Recurrent terbinafine resistant Trichophyton rubrum infection in a child with congenital ichthyosis. Pediatr Dermatol. 2018;35(2):259-60.

25 Yamada T, Maeda M, Alshahni MM, Tanaka $\mathrm{R}$, Yaguchi T, Bontems O, et al. Terbinafine resistance of Trichophyton clinical isolates caused by specific point mutations in the squalene epoxidase gene. Antimicrob Agents Chemother. 2017;61(7):e00115-17.

26 Osborne CS, Leitner I, Favre B, Ryder NS. Amino acid substitution in Trichophyton rubrum squalene epoxidase associated with resistance to terbinafine. Antimicrob Agents Chemother. 2005;49(7):2840-4.

27 Shen JJ, Jemec GBE, Arendrup MC, Saunte DML. Photodynamic therapy treatment of superficial fungal infections: A systematic review. Photodiagnosis Photodyn Ther. 2020 Apr;31:101774.

28 Khurana A, Sardana K, Chowdhary A. Antifungal resistance in dermatophytes: Recent trends and therapeutic implications. Fungal Genet Biol. 2019;132(May):103255.

29 Ebert A, Monod M, Salamin K, Burmester A, Uhrlaß S, Wiegand C, et al. Alarming Indiawide phenomenon of antifungal resistance in dermatophytes: A multicentre study. Mycoses. 2020;63(7):717-28.

30 Shenoy M, Jayaraman J. Epidemic of difficultto-treat tinea in India: Current scenario, culprits, and curbing strategies. Arch Med Heal Sci. 2019;7(1):112.

31 Dogra S, Shaw D, Rudramurthy S. Antifungal drug susceptibility testing of dermatophytes: Laboratory findings to clinical implications. Indian Dermatol Online J. 2019;10(3):225-33.

32 Verma SB, Zouboulis C. Indian irrational skin creams and steroid-modified dermatophytosis - an unholy nexus and alarming situation. J Eur Acad Dermatol Venereol. 2018;32(11): e426-7.

33 Verma S, Madhu R. The Great Indian Epidemic of Superficial Dermatophytosis: An Appraisal. Indian J Dermatol. 2017;62(3): 227-36.

34 Hiruma J, Kitagawa H, Noguchi H, Kano R, Hiruma M, Kamata $\mathrm{H}$, et al. Terbinafine-resistant strain of Trichophyton interdigitale strain isolated from a tinea pedis patient. J Dermatol. 2019;46(4):351-3.

35 Fattahi A, Shirvani F, Ayatollahi A, RezaeiMatehkolaei A, Badali H, Lotfali E, et al. Multidrug-resistant Trichophyton mentagrophytes genotype VIII in an Iranian family with generalized dermatophytosis: report of four cases and review of literature. Int J Dermatol. 2020:1-7. 
36 Süß A, Uhrlaß S, Ludes A, Verma SB, Monod $M$, Krüger $C$, et al. [Extensive tinea corporis due to a terbinafine-resistant Trichophyton mentagrophytes isolate of the Indian genotype in a young infant from Bahrain in Germany]. Hautarzt. 2019 Nov;70(11):888-96.

37 Nenoff P, Verma SB, Ebert A, Süß A, Fischer E, Auerswald E, et al. Spread of TerbinafineResistant Trichophyton mentagrophytes Type VIII (India) in Germany - The Tip of the Iceberg? J Fungi. 2020;6(4):207.

38 Łagowski D, Gnat S, Nowakiewicz A, Osińska M, Dyląg M. Intrinsic resistance to terbinafine among human and animal isolates of Trichophyton mentagrophytes related to amino acid substitution in the squalene epoxidase. Infection. 2020:8-11.

39 Sacheli R, Harag S, Dehavay F, Evrard S, Rousseaux D, Adjetey A, et al. Belgian National Survey on Tinea Capitis: Epidemiological Considerations and Highlight of Terbinafine-Resistant T. mentagrophytes with a Mutation on SQLE Gene. J Fungi (Basel). 2020;6(4):195.

40 EUCAST EC on AST. EUCAST definitions of clinical breakpoints and epidemiological cutoff values Clinical resistance and clinical breakpoints Microbiological resistance and epidemiological cut-off values ( ECOFF) [Internet]. 2013 Available from: http://www.eucast.org/fileadmin/src/media/PDFs/EUCAST_files/EUCAST_SOPs/EUCAST_definitions_of_clinical_breakpoints_and_ ECOFFs.pdf

41 Johnson EM, Arendrup MC. Susceptibility Test Methods: Yeasts and Filamentous Fungi. In: Carroll P, Landry MA, Patel R, editors, et al. Manual of Clinical Microbiology. 12th ed. London: Wiley; 2019. p. 2351-76.

42 CLSI. Reference method for broth dilution antifungal susceptibility testing of filamentous fungi; approved standard. CLSI document M38- A2. CLSI, Wayne, PA. [Internet]. 2008;(April). Available from: https://clsi.org/ media/1455/m38a2_sample.pdf

43 Arendrup MC, Kahlmeter G, Guinea J, Meletiadis J. How to: perform antifungal susceptibility testing of microconidia-forming dermatophytes following the new reference EUCAST method E.Def 11.0, exemplified by Trichophyton. Clin Microbiol Infect. 2020.

44 Arendrup MC, Cuenca-Estrella M, Lass-Flörl C, Hope WW. Breakpoints for antifungal agents: an update from EUCAST focussing on echinocandins against Candida spp. and triazoles against Aspergillus spp. Drug Resist Updat. 2013 Dec;16(6):81-95.

45 Moher D, Liberati A, Tetzlaff J, Altman DG, Altman D, Antes G, et al. Preferred reporting items for systematic reviews and meta-analyses: The PRISMA statement. BMJ. 2009; 339(7):b2535.

46 Khurana A, Masih A, Chowdhary A, Sardana K, Borker S, Gupta A, et al. Correlation of in vitro susceptibility based on MICs and squalene epoxidase mutations with clinical response to terbinafine in patients with TINEa corporis/cruris. Antimicrob Agents Chemother. 2018 Oct;62(12):1-9.

47 Pathania S, Rudramurthy SM, Narang T, Saikia UN, Dogra S. A prospective study of the epidemiological and clinical patterns of recurrent dermatophytosis at a tertiary care hospital in India. Indian J Dermatol Venereol Leprol. 2018;84(6):678-84.

48 Arendrup MC, Jørgensen KM, Guinea J, Lagrou $\mathrm{K}$, Chryssanthou $\mathrm{E}$, Hayette $\mathrm{M}$, et al. Multicentre validation of a EUCAST method for the antifungal susceptibility testing of microconidia-forming dermatophytes. J Antimicrob Chemother. 2020;75:1807-19.

49 Ghannoum M, Isham N, Herbert J, Henry W, Yurdakul S. Activity of TDT 067 (terbinafine in transfersome) against agents of onychomycosis, as determined by minimum inhibitory and fungicidal concentrations. J Clin Microbiol. 2011;49(5):1716-20.

50 Verma S, Saraswat A, Rao P, Dogra S. Topical itraconazole formulations: Unscrupulous pharmaceutical companies and lax Indian drug regulators endangering a precious drug. Indian Dermatol Online J. 2020;11(5):80611.

51 Singh SK, Patwa DK, Tilak R, Das A, Singh TB. In vitro susceptibility of dermatophytes to oral antifungal drugs and amphotericin $B$ in Uttar Pradesh, India. Indian J Dermatol Venereol Leprol. 2019;85(4):388-92.

52 Rengasamy M, Shenoy M, Dogra S, Asokan $\mathrm{N}$, Khurana A, Poojary S, et al. Indian association of dermatologists, venereologists and leprologists (IADVL) task force against recalcitrant tinea (ITART) consensus on the management of glabrous tinea (INTACT). Indian Dermatol Online J. 2020;11(4):502-19.

53 Rajagopalan M, Inamadar A, Mittal A, Miskeen AK, Srinivas CR, Sardana K, et al. Expert Consensus on The Management of Dermatophytosis in India (ECTODERM India). BMC Dermatol. 2018;18(1):6-11.

54 Monod M, Feuermann M, Salamin K, Fratti M, Makino M, Alshahni MM, et al. Trichophyton rubrum Azole Resistance Mediated by a New ABC Transporter, TruMDR3. Antimicrob Agents Chemother. 2019 Nov;63(11): e00863-19.

55 Ito K, Takeuchi H, Tomomatsu S. A study on griseofulvin. II. Dermatophyton relatively resistant to griseofulvin. Bull Pharm Res Inst. 1960 Nov;29:10-5.

56 Rosenthal SA, Wise RS. Studies concerning the development of resistance to griseofulvin by dermatophytes. Arch Dermatol. 1960 May; 81:684-9.

57 Mukherjee PK, Leidich SD, Isham N, Leitner I, Ryder NS, Ghannoum MA. Clinical Trichophyton rubrum strain exhibiting primary resistance to terbinafine. Antimicrob Agents Chemother. 2003 Jan;47(1):82-6.

58 Martinez-Rossi NM, Bitencourt TA, Peres NTA, Lang EAS, Gomes EV, Quaresemin NR, et al. Dermatophyte resistance to antifungal drugs: Mechanisms and prospectus. Front Microbiol. 2018;9(MAY):1108-18.
59 Singh A, Masih A, Monroy-Nieto J, Singh PK, Bowers J, Travis J, et al. A unique multidrugresistant clonal Trichophyton population distinct from Trichophyton mentagrophytes/ Trichophyton interdigitale complex causing an ongoing alarming dermatophytosis outbreak in India: genomic insights and resistance profile. Fungal Genet Biol. 2019 Dec; 133:103266.

60 Ghelardi E, Celandroni F, Gueye SA, Salvetti $S$, Senesi S, Bulgheroni A, et al. Potential of Ergosterol synthesis inhibitors to cause resistance or cross-resistance in Trichophyton rubrum. Antimicrob Agents Chemother. 2014 May;58(5):2825-9.

61 Clinical and Laboratory Standards Institute (CLSI). Reference Method for Broth Dilution Antifungal Susceptibility And, Filamentous Fungi. 3rd ed. CLSI standard M38. 2018

62 Shehata AS, Mukherjee PK, Ghannoum MA. Comparison between the standardized Clinical and Laboratory Standards Institute M38A2 method and a 2,3-bis(2-methoxy-4-nitro5-[(sulphenylamino) carbonyl]-2H-tetrazolium hydroxide-based method for testing antifungal susceptibility of dermatophytes. J Clin Microbiol. 2008;46(11):3668-71.

63 De Almeida LMM, Souza EADF, Bianchin DB, Svidzinski TIE. In vitro response of cutaneous mycosis fungal agents to the most widely used systemic antifungals in dermatology. An Bras Dermatol. 2009;84(3):24955.

64 Cetinkaya Z, Kiraz N, Karaca S, Kulac M, Ciftci IH, Aktepe OC, et al. Antifungal susceptibilities of dermatophytic agents isolated from clinical specimens. Eur J Dermatol. 2005; 15(4):258-61.

65 Fernández-Torres B, Carrillo AJ, Martin E, Del Palacio A, Moore MK, Valverde A, et al. In vitro activities of 10 antifungal drugs against 508 dermatophyte strains. Antimicrob Agents Chemother. 2001;45(9):2524-8.

66 Behnam M, Zarrinfar H, Najafzadeh MJ, Naseri A, Jarahi L, Novak Babič M. Low in vitro activity of sertaconazole against clinical isolates of dermatophyte. Curr Med Mycol. 2020;6(1):36-41.

67 Allahdadi M., Hajihossein R., Kord M., Rahmati E., Amanloo S., Didehdar M. Molecular characterization and antifungal susceptibility profile of dermatophytes isolated from scalp dermatophyte carriage in primary school children in Arak city, Center of Iran. Journal de Mycologie Médicale. 2019;29(1):19-23.

68 Rezaei-Matehkolaei A, Khodavaisy S, Alshahni MM, Tamura T, Satoh K, Abastabar $M$, et al. In Vitro Antifungal Activity of Novel Triazole Efinaconazole and Five Comparators against Dermatophyte Isolates. Antimicrob Agents Chemother. 2018;62(5).

69 Carreira A, Ferreira JB, Pereira I, Ferreira J, Filipe P, Ferreira RB, et al. Blad-containing oligomer: a novel fungicide used in crop protection as an alternative treatment for tinea pedis and tinea versicolor. Journal of Medical Microbiology. 2018;67(2):198-207. 
70 Dabas Y, Xess I, Singh G, Pandey M, Meena S. Molecular Identification and Antifungal Susceptibility Patterns of Clinical Dermatophytes Following CLSI and EUCAST Guidelines. JoF. 2017;3(2):17.

71 Afshari MA, Shams-Ghahfarokhi M, Razzaghi-Abyaneh M. Antifungal susceptibility and virulence factors of clinically isolated dermatophytes in Tehran, Iran. Iran J Microbiol. 2016;8(1):36-46. 27092223.

72 Ansari S, Hedayati MT, Zomorodian K, Pakshir K, Badali H, Rafiei A, et al. Molecular Characterization and In Vitro Antifungal Susceptibility of 316 Clinical Isolates of Dermatophytes in Iran. Mycopathologia. 2015; 181(1-2):89-95.

73 Tamura T, Asahara M, Yamamoto M, Yamaura $\mathrm{M}$, Matsumura $\mathrm{M}$, Goto $\mathrm{K}$, et al. In vitro susceptibility of dermatomycoses agents to six antifungal drugs and evaluation by fractional inhibitory concentration index of combined effects of amorolfine and itraconazole in dermatophytes. Microbiol Immunol. 2014; $58(1): 1-8$.

74 Silva L.B., de Oliveira D.B.C., da Silva B.V., de Souza R.A., da Silva P.R., Ferreira-Paim K., et al. Identification and antifungal susceptibility of fungi isolated from dermatomycoses. J Eur Acad Dermatol Venereol. 2013;28(5):633640.

75 Magagnin CM, Stopiglia CDO, Vieira FJ, Heidrich D, Machado M, Vetoratto G, et al. Perfil de suscetibilidade a antifúngicos de dermatófitos isolados de pacientes com insuficiência renal crônica. An. Bras. Dermatol. 2011;86(4):694-701.

76 Rudramurthy Shivaprakash M, Shankarnarayan Shamanth A, Dogra Sunil, Shaw Dipika, Mushtaq Khurram, Paul Raees A, et al. Mutation in the Squalene Epoxidase Gene of Trichophyton interdigitale and Trichophyton rubrum Associated with Allylamine Resistance. Antimicrob Agents Chemother. 2018; 62(5). http://dx.doi.org/10.1128/AAC.0252217. 29530857.

77 Markantonatou AM, Samaras K, Zachrou E, Vyzantiadis TA. Comparison of Four Methods for the in vitro Susceptibility Testing of Dermatophytes. Front. Microbiol. 2020;11: 1-11.

78 Gnat Sebastian, Łagowski Dominik, Nowakiewicz Aneta, Osińska Marcelina, Kopiński Łukasz. Population differentiation, antifungal susceptibility, and host range of Trichophyton mentagrophytes isolates causing recalcitrant infections in humans and animals. Eur J Clin Microbiol Infect Dis. 2020;39(11): 2099-2113.

79 Filho Antonio M.S., Ventura Carlucci G., Criado Paulo R., Del Negro Gilda B., Freitas Roseli S., Luiz Olinda C., et al. Hemodialysis and Kidney Transplantation as Predisposing Conditions to Onychomycosis. Nephron. 2017;137(1):38-46
$80 \mathrm{Oz}$ Yasemin, Qoraan Iman, Oz Ali, Balta Ilknur. Prevalence and epidemiology of tinea pedis and toenail onychomycosis and antifungal susceptibility of the causative agents in patients with type 2 diabetes in Turkey. Int J Dermatol. 2016;56(1):68-74.

81 Muangkaew Watcharamat, Wongsuk Thanwa, Luplertlop Natthanej. Common dermatophytes and in vitro anti-fungal susceptibility testing in patients attending the Dermatological Clinic at the Hospital for Tropical Medicine, Bangkok. New Microbiol. 2017;40(3): 175-179.

82 Bhatia VK, Sharma PC. Determination of minimum inhibitory concentrations of itraconazole, terbinafine and ketoconazole against dermatophyte species by broth microdilution method. Indian Journal of Medical Microbiology. 2015;33(4):533-537.

83 Badali Hamid, Mohammadi Rasoul, Mashedi Olga, de Hoog G. Sybren, Meis Jacques F. In vitro susceptibility patterns of clinically important Trichophyton and Epidermophyton species against nine antifungal drugs. Mycoses. 2015;58(5):303-307.

84 Yenişehirli Gülgün, Tunçoğlu Ebru, Yenişehirli Aydan, Bulut Yunus. In vitro activities of antifungal drugs against dermatophytes isolated in Tokat, Turkey. International Journal of Dermatology. 2013;52(12): $1557-1560$

85 Adimi Parvaneh, Hashemi Seyed Jamal, Mahmoudi Mahmood, Mirhendi Hossein, Shidfar Mohammad Reza, Emmami Masood, et al. In-vitro Activity of 10 Antifungal Agents against 320 Dermatophyte Strains Using Microdilution Method in Tehran. Iran J Pharm Res. 2013;12(3):537-45.

86 Jo Siu William J., Tatsumi Yoshiyuki, Senda Hisato, Pillai Radhakrishnan, Nakamura Takashi, Sone Daisuke, et al. Comparison of In Vitro Antifungal Activities of Efinaconazole and Currently Available Antifungal Agents against a Variety of Pathogenic Fungi Associated with Onychomycosis. Antimicrob. Agents Chemother. 2013;57(4):1610-1616.

87 Coulibaly Oumar, Alhanout Kamel, L'Ollivier Coralie, Brunel Jean-Michel, Thera Mahamadou A, Dijimdé Abdoulaye A, et al. In vitro activity of aminosterols against dermatophytes. Med Mycol. 2013;51(3):309-312.

88 Irimie Marius, Tătaru Alexandru, Oantă Alexandru, Moga Marius. In vitro susceptibility of dermatophytes isolated from patients with end-stage renal disease: a case-control study. Mycoses. 2013;57(3):129-134.

89 Özcan D, Seçkin D, Demirbilek M. In vitro antifungal susceptibility of dermatophyte strains causing tinea pedis and onychomycosis in patients with non-insulin-dependent diabetes mellitus: a case-control study. Journal of the European Academy of Dermatology and Venereology. 2010;24(12):1442-1446.
90 Zhang Jing, Chen Jian, Huang Huai-Qiu, Xi Li-Yan, Lai Wei, Xue Ru-Zeng, et al. Comparison of a glucose consumption based method with the CLSI M38-A method for testing antifungal susceptibility of Trichophyton rubrum and Trichophyton mentagrophytes. Chin Med J (Engl). 2010;123(14): 1909-14.

91 Mota Crystiane Rodrigues Araújo, Miranda Karla Carvalho, Lemos Janine de Aquino, Costa Carolina Rodrigues, Souza Lúcia Kioko Hasimoto e, Passos Xisto Sena, et al. Comparison of in vitro activity of five antifungal agents against dermatophytes, using the agar dilution and broth microdilution methods. Rev. Soc. Bras. Med. Trop. 2009;42(3):250254.

92 Araújo Crystiane Rodrigues, Miranda Karla Carvalho, Fernandes Orionalda de Fatima Lisboa, Soares Ailton José, Silva Maria do Rosário Rodrigues. In vitro susceptibility testing of dermatophytes isolated in Goiania, Brazil, against five antifungal agents by broth microdilution method. Rev. Inst. Med. trop. S. Paulo. 2009;51(1):9-12.

93 Koga Hiroyasu, Nanjoh Yasuko, Makimura Koichi, Tsuboi Ryoji. In vitro antifungal activities of luliconazole, a new topical imidazole. Med Mycol. 2009;47(6):640-647.

94 Singh Jagpal, Singh Jagpal, Zaman Muhammad, Gupta Aditya K. Evaluation of microdilution and disk diffusion methods for antifungal susceptibility testing of dermatophytes. Med Mycol. 2007;45(7):595-602.

95 Barros Maria Elisabete da Silva, Santos Daniel de Assis, Hamdan Júnia Soares. Evaluation of susceptibility of Trichophyton mentagrophytes and Trichophyton rubrum clinical isolates to antifungal drugs using a modified CLSI microdilution method (M38-A). Journal of Medical Microbiology. 2007;56(4):514518

96 Barros Maria Elisabete da Silva, Santos Daniel de Assis, Hamdan Júnia Soares. In vitro methods for antifungal susceptibility testing of Trichophyton spp. Mycological Research. 2006;110(11):1355-1360.

97 Esteban A., Abarca M. L., Cabañes F. J. Comparison of disk diffusion method and broth microdilution method for antifungal susceptibility testing of dermatophytes. Med Mycol. 2005;43(1):61-66.

98 Alió S A. B., Mendoza M., Zambrano E. A., Díaz E., Cavallera E. Dermatophytes growth curve and in vitro susceptibility test: a broth micro-titration method. Med Mycol. 2005; 43(4):319-325.

99 Gupta A.K., Kohli Y. In vitro susceptibility testing of ciclopirox, terbinafine, ketoconazole and itraconazole against dermatophytes and nondermatophytes, and in vitro evaluation of combination antifungal activity. $\mathrm{Br} J$ Dermatol. 2003;149(2):296-305. 
100 Jessup C J, Warner J, Isham N, Hasan I, Ghannoum M A. Antifungal susceptibility testing of dermatophytes: establishing a medium for inducing conidial growth and evaluation of susceptibility of clinical isolates. J Clin Microbiol. 2000;38(1):341-4.

101 Jessup C. J., Ghannoum M. A., Ryder N. S. An evaluation of the in vitro activity of terbinafine. Med Mycol. 2000;38(2):155-159.

102 Norris Heather A., Elewski Boni E., Ghannoum Mahmoud A. Optimal growth conditions for the determination of the antifungal susceptibility of three species of dermatophytes with the use of a microdilution method. Journal of the American Academy of Dermatology. 1999;40(6):S9-S13.

103 Santos D. A., Hamdan J. S. In vitroantifungal oral drug and drug-combination activity against onychomycosis causative dermatophytes. Med Mycol. 2006;44(4):357-362.

104 Korting H. C., Ollert M., Abeck D. Results of German multicenter study of antimicrobial susceptibilities of Trichophyton rubrum and Trichophyton mentagrophytes strains causing tinea unguium. German Collaborative Dermatophyte Drug Susceptibility Study Group. Antimicrobial Agents and Chemotherapy. 1995;39(5):1206-1208.
105 Mohd Nizam Tzar, Binting Rabiatul Adawiyah Ag, Mohd Saari Shafika, Kumar Thivyananthini Vijaya, Muhammad Marianayati, Satim Hartini, et al. In Vitro Antifungal Activities against Moulds Isolated from Dermatological Specimens. Malays J Med Sci. 2016;23(3):32-9. 27418867.

106 Azambuja Christiane Venske de Almeida, Pimmel Luciana Alves, Klafke Gabriel Baracy, Xavier Melissa Orzechowski. Onychomycosis: clinical, mycological and in vitro susceptibility testing of isolates of Trichophyton rubrum. An. Bras. Dermatol. 2014 89(4):581-586.

107 Coelho L. M., Aquino-Ferreira R., Maffei C. M.L., Martinez-Rossi N. M. In vitro antifungal drug susceptibilities of dermatophytes microconidia and arthroconidia. Journal of Antimicrobial Chemotherapy. 2008;62(4): 758-761.

108 Sarifakioglu E., Seçkin D., Demirbilek M., Can F. In vitro antifungal susceptibility patterns of dermatophyte strains causing tinea unguium. Clin Exp Dermatol. 2007;32(6): 675-679.
109 de Assis Santos Daniel, de Carvalho Araújo Roberta Amália, Kohler Lidiane Meire, Machado-Pinto Jackson, Hamdan Júnia Soares, Cisalpino Patrícia Silva. Molecular typing and antifungal susceptibility of Trichophyton rubrum isolates from patients with onychomycosis pre- and posttreatment. International Journal of Antimicrobial Agents. 2007;29(5):563-569.

110 Gupta Aditya K., Kohli Yatika. Evaluation of in vitro Resistance in Patients with Onychomycosis Who Fail Antifungal Therapy. Dermatology. 2003;207(4):375-380.

111 Fernández-Torres B., Pereiro M., Guarro J. Comparison of Two Methods for Antifungal Susceptibility Testing of Trichophyton rubrum. Eur J Clin Microbiol Infect Dis. 2002;21(1):70-71.

112 Fernández-Torres B., Vázquez-Veiga H., Llovo X., Pereiro Jr. M., Guarro J. In vitro Susceptibility to Itraconazole, Clotrimazole, Ketoconazole and Terbinafine of 100 Isolates of Trichophyton rubrum. Chemotherapy. 2000;46(6):390-394.

113 Bradley M. C., Leidich S., Isham N., Elewski B. E., Ghannoum M. A. Antifungal susceptibilities and genetic relatedness of serial Trichophyton rubrum isolates from patients with onychomycosis of the toenail. Mycoses. 1999;42:105-110. 